\title{
Badania korrugacji kół pojazdów szynowych
}

\begin{abstract}
Artykut zawiera wyniki badań korugacji koła pojazdów szynowych. Praca dotyczy problemu zjawisk kontaktowych wywolanych tarciem zwrotnym. W praktyce ten rodzaj zużycia występuje na powierzchni ciernej kół zestawów kołowych pojazdów szynowych jako równomiernie rozłożone wzniesienia i wgtębienia - określane jako zużycie krrugacyjne. Autor $w$ swoich badaniach, dotyczacych rozwiqzania tego złożonego problemu, przeprowadzit badania statystyczne, numeryczna symulacje komputerowa, badania stanowiskowe oraz badania eksploatacyjne na obiekcie rzeczywistym. W badaniach uwzględniono wptyw charakterystyk wspótczynnika tarcia na powstawanie zużcia korrugacyjnego. Zużyciu korrugacyjnemu towarzyszy zjawisko wywołane tarciem zwrotnym typu przyleganie - poślizg. $W$ literaturze spotyka się nazwy tego zużycia określane jako zjawiska kontaktowe typu stick-slip.
\end{abstract}

\section{Badania stanowiskowe}

Zestawy kołowe pojazdów szynowych (rys. 1) należą do tych elementów, które decydują w największym stopniu o bezpieczeństwie eksploatowanego pojazdu i jednocześnie podlegają największym obciążeniom. Trwałość zestawów kołowych jest w tym ujęciu determinowana głównie przez intensywność procesu zużycia, [8].

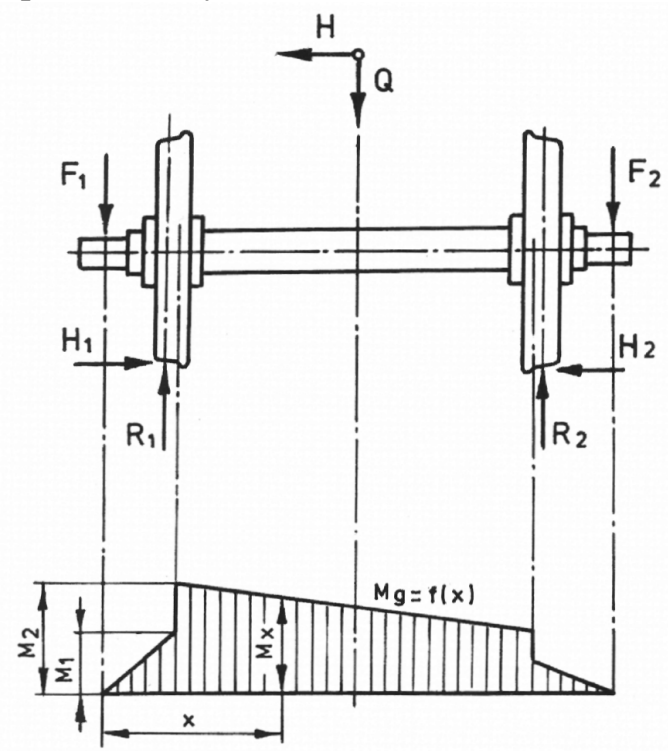

Rys. 1. Układ obciążeń oraz przebieg momentów gnących osi zestawu kołowego w czasie ruchu pojazdu szynowego

Przeprowadzone przez autora liczne obserwacje zmian makropowierzchni ciernej koła zestawów kołowych wagonów wyposażonych w hamulce tarczowe lub klockowe oraz wykonane liczne pomiary owalizacji kół i korrugacji na powierzchni tocznej koła dały podstawę do stwierdzenia, że wagony $\mathrm{z}$ hamulcem tarczowym wykazują owalizację kół, (rys. 2) natomiast wagony $\mathrm{z}$ hamulcem klockowym wykazują korrugację na powierzchni kół w strefie kontaktu koła z wstawką hamulca klockowego, rys.3.

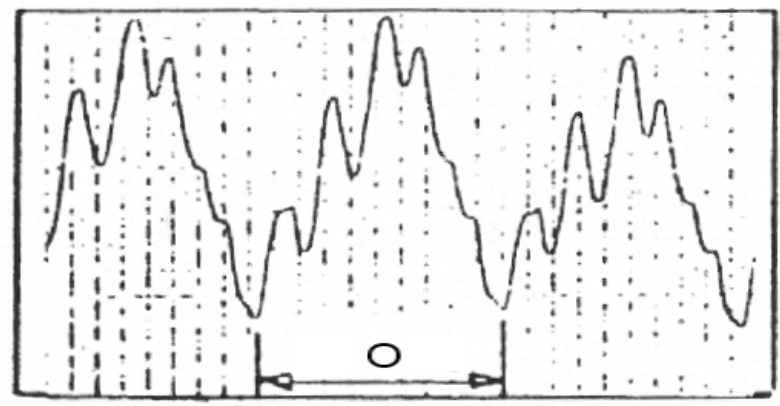

Rys. 2. Wyniki pomiaru owalizacji kół wagonu osobowego wyposażonego w hamulec tarczowy: $\mathrm{O}$ - obwód koła

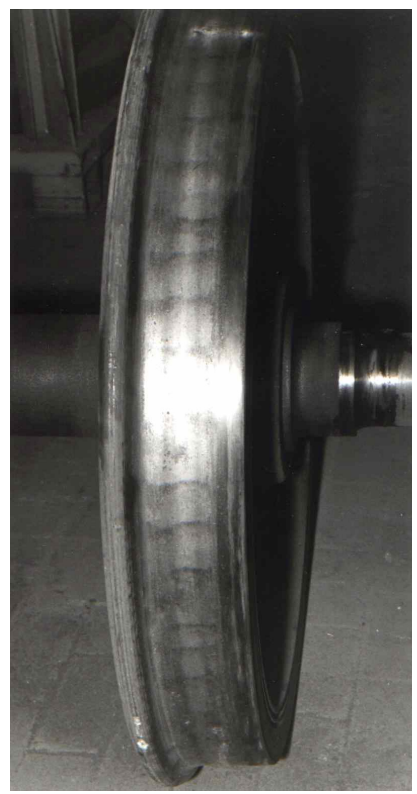

Rys. 3. Widok ogólny korrugacji na powierzchni tocznej koła wagonu wyposażonego w hamulec klockowy 


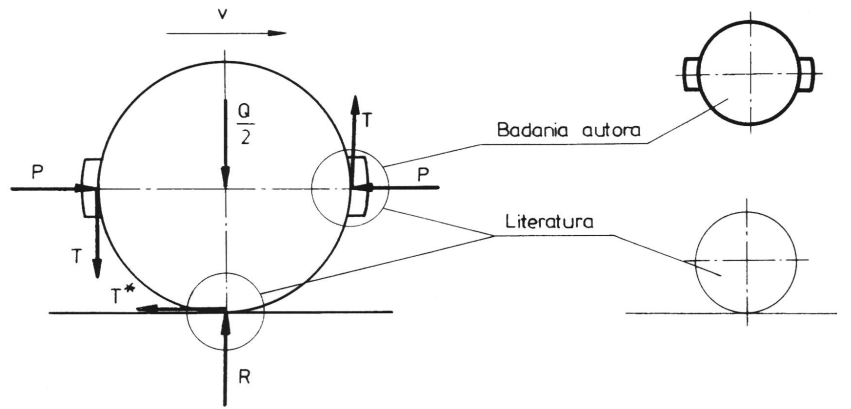

Rys.4. Rysunek poglądowy ilustrujący obszar prowadzonej przez autora analizy zjawisk kontaktowych

Badania eksperymentalne powstawania zjawisk kontaktowych typu stick-slip, występujących w miejscu styku klocka hamulcowego z kołem, autor przeprowadził w Ośrodku Badawczym DB w Minden na stanowisku badawczym, rys. 5, gdzie energia kinetyczna wirujących mas bezwładności jest zamieniana na pracę sił tarcia między klockiem a kołem.

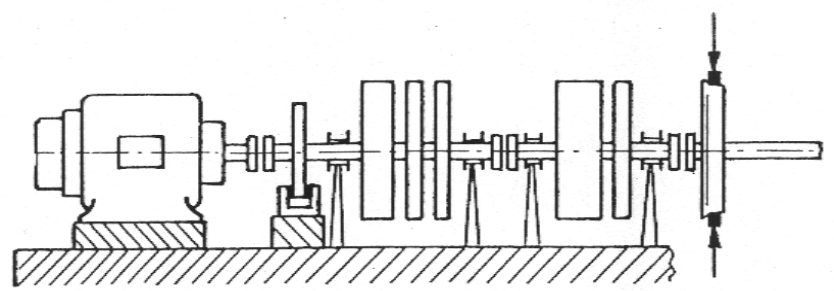

Rys.5. Schemat ogólny stanowiska badawczego do badań współpracy, w skali 1:1, koła z wstawkami klocka hamulcowego

W badaniach stanowiskowych uwzględniono, między innymi, dwa rodzaje wstawek hamulcowych Wo - wstawki żeliwne oraz Wx - wstawki prasowane z proszków metali, których rozkład wartości współczynnika tarcia zobrazowano na rys. 6 .

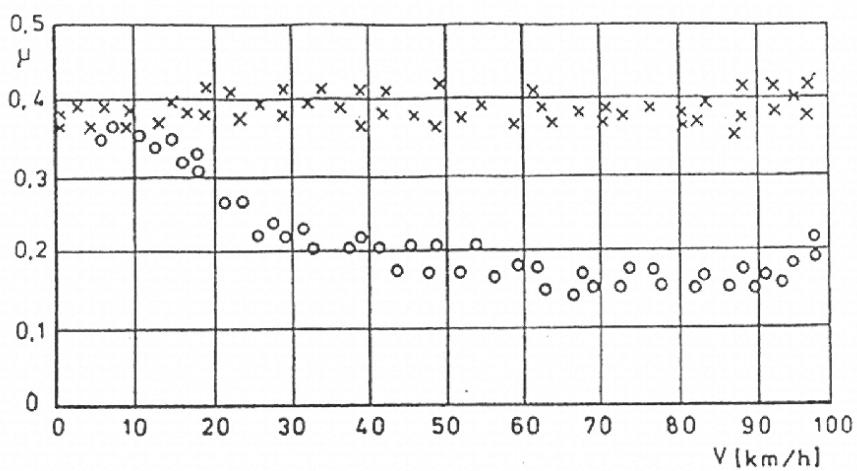

Rys. 6. Wartości współczynnika tarcia: $\mathrm{x}$ - wstawki hamulcowe wykonane z prasowanych proszków metali, o - wstawki hamulcowe odlewane z żeliwa

Podczas prób hamowania na stanowisku bezwładnościowym zachowywano rzeczywiste parametry hamowania wagonu. Koło hamowane wstawkami Wx, prasowanymi z proszków metali, charakteryzujące się stałym współczynnikiem tarcia (rys. 6), nie wykazywało korrugacji na powierzchni ciernej, rys. 7.

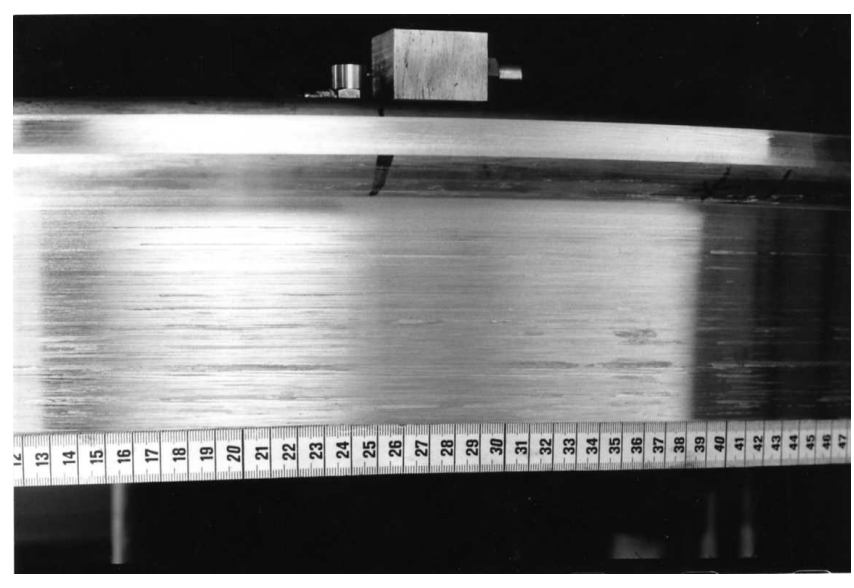

Rys. 7. Widok ogólny powierzchni ciernej koła po hamowaniu wstawkami Wx

Koło hamowane wstawkami Wo, gdzie współczynnik tarcia, (rys. 6), jest zależny od prędkości względnej koła i wstawki, wykazywało zużycie korrugacyjne, rys. 8. Próba hamowania była przeprowadzona, w tym przypadku, dla prędkości $100 \mathrm{~km} / \mathrm{h}$ i nacisku klocka hamulcowego 0,4 MPa.

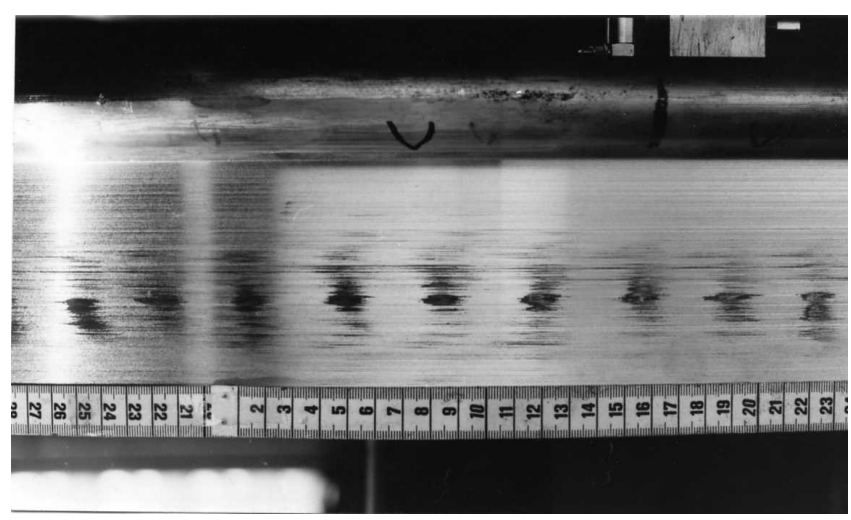

Rys. 8. Widok ogólny powierzchni ciernej koła po hamowaniu wstawkami Wo

Widoczna podziałka, przyłożona do powierzchni ciernej koła, pozwala na odczytanie w centymetrach średniej wartości odległości pomiędzy widocznymi obszarami i obliczenia wartości częstotliwości stycznych przyspieszeń wstawki hamulcowej.

Próby hamowania na stanowisku bezwładnościowym odpowiadały masie 8 ton przypadającej na 1 koło wagonu.

Jako optymalne warunki powstawania korrugacji koła należy wymienić:

- hamowanie wstawkami Wo,

- hamowanie do zatrzymania z prędkości 100 $\mathrm{km} / \mathrm{h}$,

- docisk klocka do koła 0,4 MPa,

Ukształtowanie się makroobrazu korrugacji koła stwierdzono już po 10 sekundach trwania próby hamowania. Należy zaznaczyć, że czas trwania próby hamowania $\mathrm{z}$ prędkości $100 \mathrm{~km} / \mathrm{h}$ do zatrzymania koła wynosi około 90 sekund. 


\section{Badania symulacyjne}

Badania symulacyjne ruchu klocka hamulcowego przeprowadzono dla układu mechanicznego, opisanego równaniem różniczkowym drugiego rzędu (1):

$$
m \cdot \ddot{x}+d \cdot \dot{x}+c \cdot x=\mu \cdot F_{N} \cdot \operatorname{sgn}(\dot{x}-v),
$$

gdzie:

$m$ - masa skupiona klocka hamulcowego,

$d$ - współczynnik thumienia,

$c$ - stała sprężystości,

$F_{N}$ - siła normalna,

$\mu$ - współczynnik tarcia,

$x$ - przemieszczenie.

Prędkość liniowa koła $v$ w miejscu styku $\mathrm{z}$ wstawką hamulcową występuje w tym równaniu niejawnie; jest ukryta w wyrażeniu na współczynnik tarcia, rys.6.

Na podstawie symulacji komputerowej otrzymano, między innymi, czas trwania fazy przylegania (faza stick) - odcinek $A B$, rys. 9. Istnienie fazy stick limituje proces powstawania korrugacji koła, (rys. 8), [4].

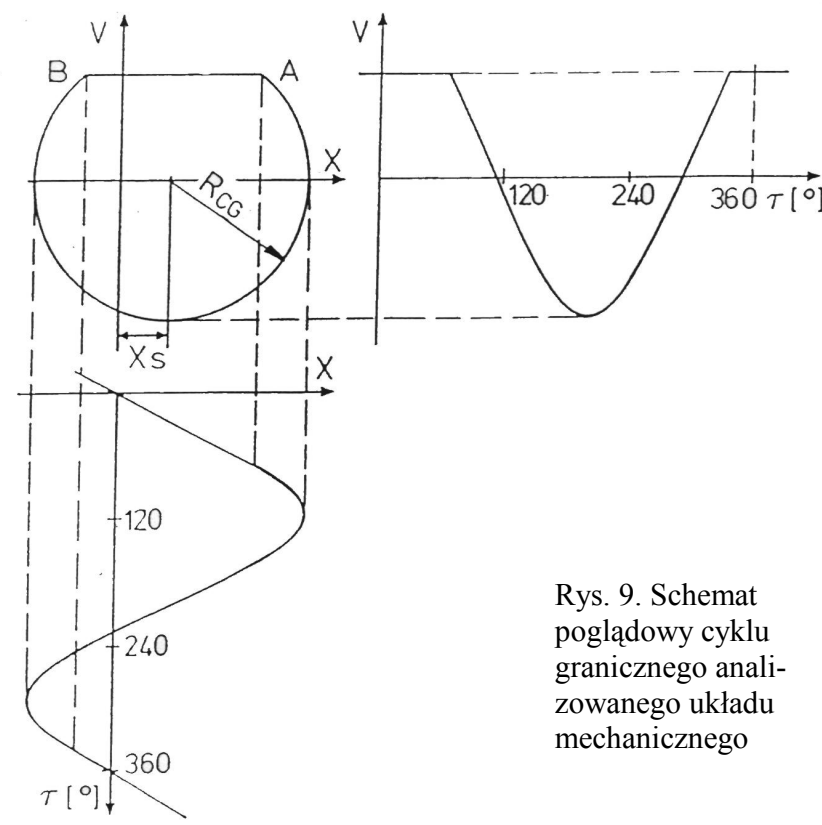

Klocek pozostaje w fazie przylegania (faza stick) tak długo, dopóki siła sprężyny równa jest maksymalnej przenoszonej sile tarcia. W tym układzie można obliczyć punkt rozdziału $X_{A}$ :

$$
x_{A}=F_{N} \cdot \mu / c
$$

w którym klocek przechodzi z fazy przylegania „stick” w fazę poślizgu klocka względem koła - „slip”.

Badania symulacyjne współpracy wstawki hamulcowej z kołem przeprowadzono dla współrzędnych bezwymiarowych (3):

$$
X^{\prime \prime}+2 \cdot \gamma \cdot X^{\prime}+X=\mu \cdot \delta \cdot\left(X^{\prime}-V\right) \cdot \operatorname{sgn}\left(X^{\prime}-V\right),
$$

gdzie:

$\mu\left(V_{r}\right)$-model tarcia w funkcji bezwymiarowej prędkości względnej,

$\gamma$ - bezwymiarowe thumienie,

$V$-bezwymiarowa prędkość koła,

$X$-bezwymiarowe przemieszczenie.

Program numerycznej symulacji zjawisk kontaktowych typu stick-slip, to jest drgań samowzbudnych klocka hamulcowego wywołanych tarciem zwrotnym, został napisany w języku PASCAL. Przykładowy wykres fazowy powstawania cyklu granicznego, podczas symulacji hamowania wstawkami Wo, przedstawiono na rys. 10.

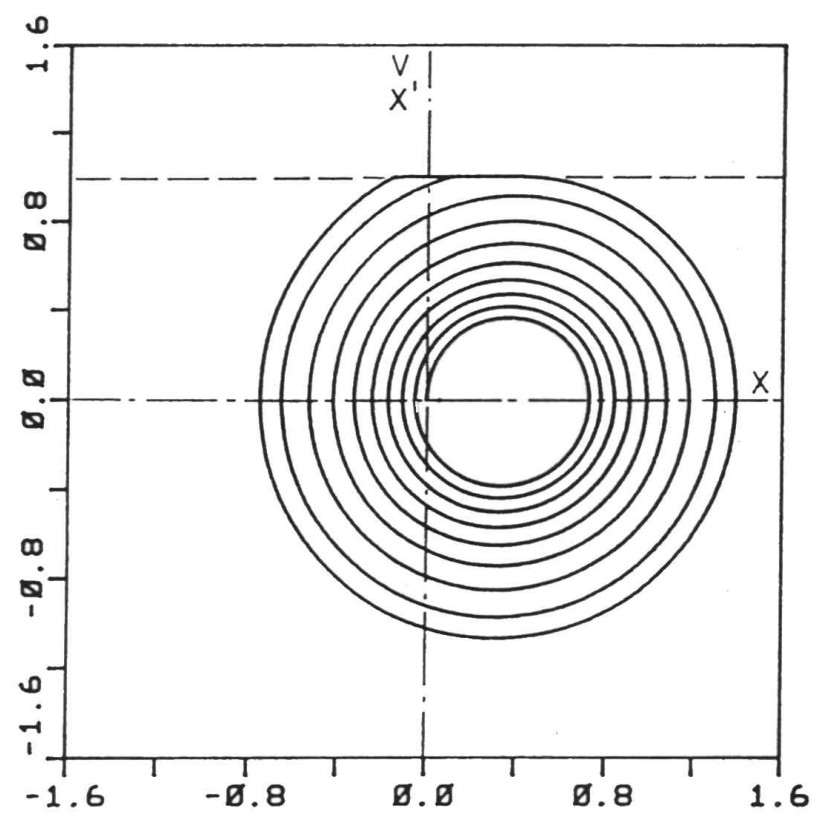

Rys. 10. Przykładowy wykres fazowy powstawania cyklu granicznego analizowanego układu mechanicznego: hamowanie wstawkami Wo: - - - - - bezwymiarowa prędkość koła $V^{\prime}, X^{\prime}$ - bezwymiarowa prędkość klocka hamulcowego

$\mathrm{Z}$ analizy wykresu na rysunku 10 wynika, że odcinek cyklu granicznego dla zerowej wartości względnej prędkości koła $V$ i klocka hamulcowego $X$, odpowiada fazie przylegania klocka do koła. Pozostała część cyklu granicznego odpowiada fazie poślizgu klocka po kole.

Na rys. 11 zamieszczono, dla przykładu, wykres fazowy powstawania cyklu granicznego, podczas symulacji hamowania wstawkami Wx.

$\mathrm{Z}$ analizy wykresu na rysunku 11 wynika, że cykl graniczny nie wykazuje fazy przylegania. Wykres cyklu odpowiada, w całym zakresie, fazie poślizgu klocka po kole.

Na podstawie przeprowadzonej analizy wyników badań symulacyjnych wpływu modelu tarcia, rys.6, na zachowanie się badanego układu mechanicznego dla współrzędnych bezwymiarowych stwierdzono, że: 
a) dla materiału Wo faza przylegania występuje, rys. 12,

b) dla materiału $\mathrm{Wx}$ faza przylegania nie występuje, rys. 13 .

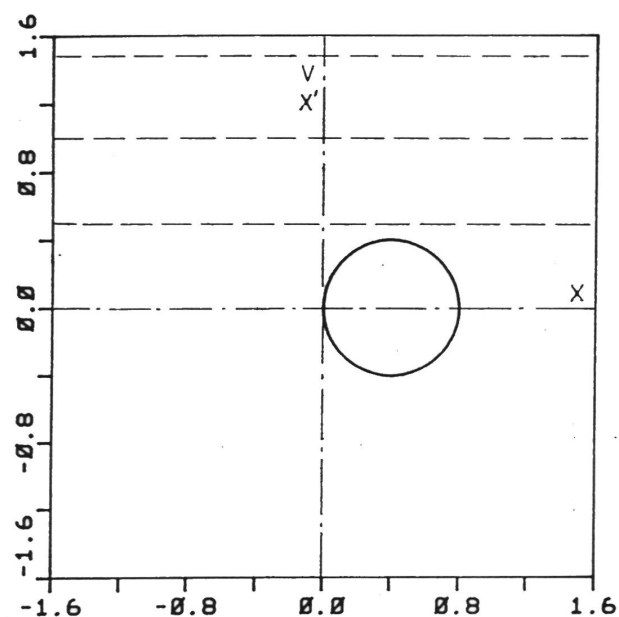

Rys. 11. Przykładowy wykres fazowy powstawania cyklu granicznego analizowanego układu mechanicznego: hamowanie wstawkami Wx: - - - - bezwymiarowa prędkość koła $V^{\prime}, X^{\prime}$ bezwymiarowa prędkość klocka hamulcowego

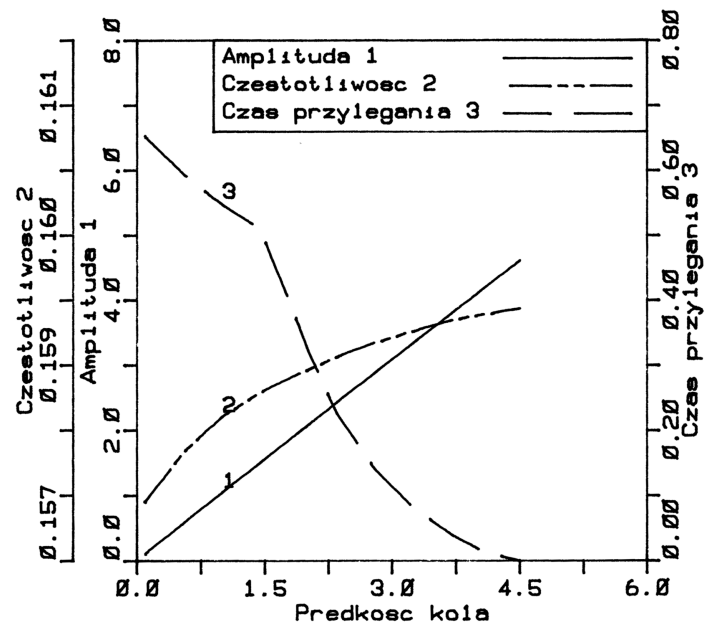

Rys. 12. Wynik badań symulacyjnych: materiał wstawki hamulcowej Wx

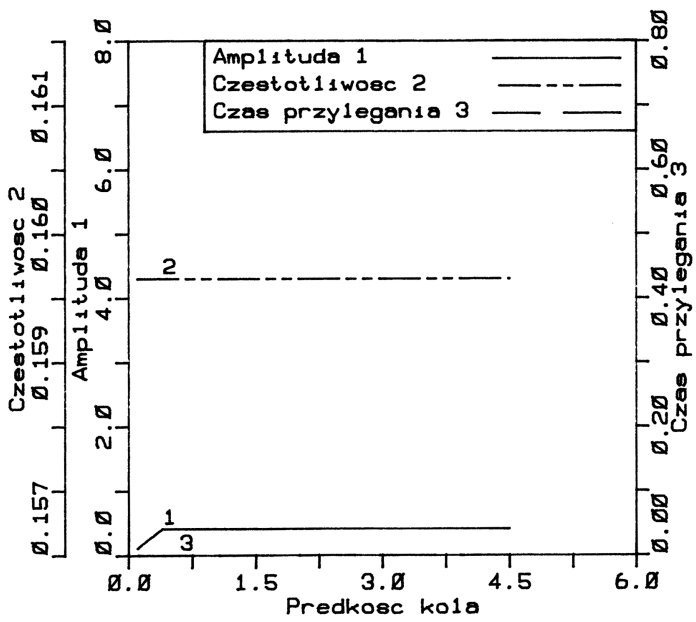

Rys. 13. Wynik badań symulacyjnych: materiał wstawki hamulcowej Wx
$\mathrm{Z}$ analizy wyników badań symulacyjnych, przedstawionych na rys. 12, wynika, że dla wstawek hamulcowych Wx faza przylegania występuje. Czas trwania fazy przylegania klocka do koła, wraz ze wzrostem prędkości koła, maleje. Po przekroczeniu prędkości granicznej koła występuje tylko faza poślizgu.

$\mathrm{Z}$ analizy wyników badań symulacyjnych, przedstawionych na rys. 1 , wynika, że dla wstawek hamulcowych Wo faza przylegania klocka do koła nie występuje.

Powyższe badania, których wyniki zamieszczono na rys.12 oraz rys. 13 , wykazały pełną zgodność w odniesieniu do wyników analizy Uetza [6] przedstawionej w formie zapisu (4);

$$
V_{g r} \geq \frac{P \cdot\left(\mu_{s}-\mu_{k}\right)}{\sqrt{c \cdot m}}
$$

Z zapisu nierówności (4) wynika, że wraz ze zmniejszeniem się wartości różnicy współczynnika tarcia statycznego i dynamicznego, $\left(\mu_{s}-\mu_{k}\right)$, zmniejsza się również wartość granicznej prędkości liniowej koła podczas hamowania $V_{g r}$, tzn. faza przylegania zostaje wyeliminowana i występuje tylko ciagły poślizg klocka po kole.

\section{Odkształcenia cieplne wstawki hamulcowej}

Materiał wstawki hamulcowej ulega podczas procesu hamowania odkształceniom cieplnym, rys.14. W pierwszej fazie hamowania wstawka hamulcowa ulega odkształceniom cieplnym, rys. 14a. W wyniku tej deformacji styk rozłożony przyjmuje formę styku skupionego w części środkowej powierzchni przylegania wstawki do koła. Tak ukształtowany styk skupiony przylegania wstawki do koła wyjaśnia powstawanie korrugacji w początkowej fazie hamowania. W kolejnej fazie hamowania następuje ponowne odkształcenie wstawki hamulcowej, rys. $14 \mathrm{~b}$. W wyniku ponownej deformacji wstawki hamulcowej styk skupiony w środkowej części wstawki przyjmuje formę kontaktu w dwóch skrajnych obszarach przylegania wstawki. a)

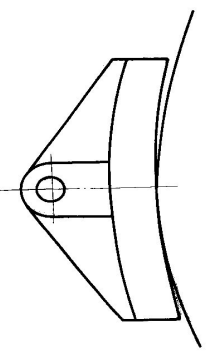

b)

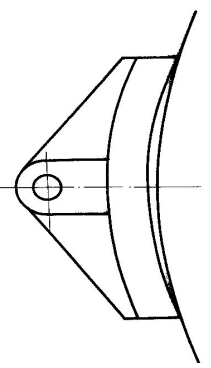

Rys. 14. Mechanizm zużywania się klasycznych wstawek hamulcowych, [7]: a) odkształcenie w pierwszej fazie hamowania - powstawanie korrugacji koła, b) kolejna faza odkształcenia. 
Na rys. 15. zamieszczono widok ogólny wstawki 3-segmentowej. Konstrukcja wstawki 3-segmentowej spowodowała wyeliminowanie deformacji cieplnej, która towarzyszy wstawkom klasycznym, przedstawionym na rysunku 14 .
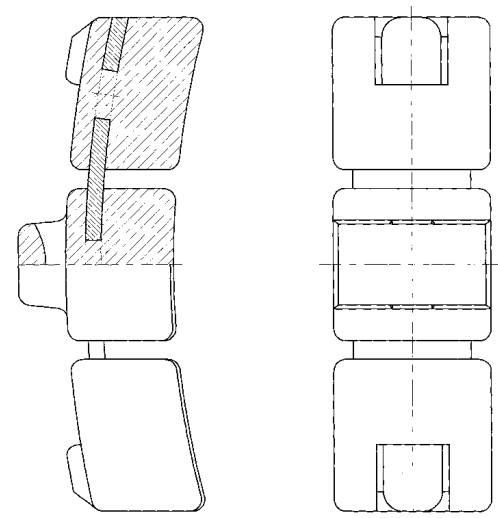

Rys. 15. Segmentowa wstawka hamulcowa, [7]

Na postawie wyników badań stanowiskowych 3segmentowych wstawek hamulcowych wykonanych z żeliwa P10 stwierdzono, między innymi, że:

- w przeciwieństwie do wstawek klasycznych nie zaobserwowano nierównomiernego zużywania się wstawek segmentowych,

- w przeciwieństwie do wstawek klasycznych nie stwierdzono występowania obszarów o wyraźnie zwiększonym obciążeniu cieplnym.

\section{Podsumowanie}

Współpracę wstawki hamulcowej z kołem, w kontekście wyeliminowania korrugacji koła, można stymulować poprzez:

- dobór materiału wstawki hamulcowej, np. materiału Wx, o stałej wartość współczynnika tarcia,

- dobór konstrukcji wstawki hamulcowe, np. wstawka wielosegmentowa,

- dobór optymalnych warunków hamowania, tzn. ogrniczenie tych parametrów hamowania, które sprzyjają procesowi inicjacji korrugacji koła.

Wprowadzenie wstawek hamulcowych Wx pozwoliło na wyeliminowanie fazy kontaktowej stick, a tym samym wyeliminowanie powstawania korrugacji koła - zużycia charakterystycznego dla klasycznych wstawek hamulcowych.

Wprowadzenie wstawek hamulcowych 3segmentowych wyeliminowało proces deformacji cieplnej, który jest obserwowany w klasycznych wstawkach hamulcowych.

Optymalizacja warunków hamowania, dla wstawek klasycznych, pozwala na wykazanie tych parametrów hamowania; prędkość $100 \mathrm{~km} / \mathrm{h}$, nacisk wstawki hamulcowej 0,4 MPa, które w szczególny sposób inicjują proces powstawania korrugacji koła.

\section{Lit e r a t u r a}

[1] Lisowski Z.: Zużycie. Zagadnienia tarcia, zużycia $i$ smarowania. Z. 6, 1969, PWN, Warszawa 1970, s. 129-1166.

[2] Piec P.: On study of phenomena in the wheel brake shoe contact area. Periodica Polytechnica, TU Budapest, Vol. 21. No. 3. 1993, Part III, s. $229 \div 238$

[3] Piec P.: Some methods of investigation of rail vehicle elements wear processes. Archiwum transportu.

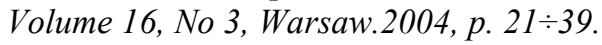

[4] Piec P.: Badania eksploatacyjne elementów i zespołów pojazdów szynowych. Wyd. Politechniki Krakowskiej, 2004.

[5] Skvor R.: Riffel - oder Polygonbildung von Schienenfahrzeugen. Verkehrstechnik in der Schweiz

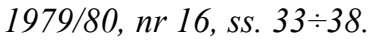

[6] Uetz H.: Tribologie - Verschleisskunde. Vorlesungsmanuskript, Universitaet Stuttgart, 1980.

[7] Urbańczyk P.: Wplyw odksztatceń cieplnych wstawek nowej konstrukcji na prace hamulca. Praca doktorska. Promotor P. Piec. Politechnika Krakowska. Kraków, 2011.

[8] Zwierzyk-Klimek.: Analiza zużycia i kosztów eksploatacji zestawów kołowych tramwajów. Praca doktorska. Promotor P. Piec. Politechnika Krakowska. 2006. 